\title{
Spontaneous Rupture of Bicornuate Uterus Caused by Levorotation Due to Congenital Band
}

\author{
Jain M, ${ }^{1}$ Tripathi $R,{ }^{1}$ Jain $\mathbf{S},{ }^{2}$ Verma A, ${ }^{2}$ Bajpai $\mathbf{N}^{3}$ \\ ${ }^{1}$ Department of Obstetrics and Gynaecology, \\ ${ }^{2}$ Department of Radiodiagnosis and Imaging, Institute of Medical Sciences, Banaras Hindu University, \\ ${ }^{3}$ Department of Obstetrics and Gynaecology, Himalayan Institute of Medical Sciences, Dehradun, India.
}

\begin{abstract}
Rupture of gravid uterus due to torsion is a rare obstetric complication. The uterus has little mobility and is firmly held in place by its supports which resist any tendency of torsion. We are reporting a case of bicornuate uterus with rupture of left horn due to inability of malformed uterus to expand and axial torsion around one of its horns held by congenital band. Band was dissected and ruptured left horn excised, hemostasis was secured leaving the nonruptured nongravid horn of uterus intact.
\end{abstract}

Keywords: bicornuate uterus, congenital band, rupture uterus.

\section{INTRODUCTION}

Rupture of gravid uterus due to torsion is a rare but serious obstetric complication. The uterus has little mobility and is firmly held in place by its supports which resist any tendency of torsion. Torsion causes venous obliteration, oedematous infilteration, distention of uterus by blood or pus and hemorrhagic infilteration in pelvic and subperitoneal tissue. Occlusion of arteries may cause necrosis of tissue. Uterine distention and tissue necrosis may ultimately lead to rupture of uterus. Uterine torsion usually ranges from 45 to $180^{\circ}$ but rarely extent of torsion varies between 200 and $360^{\circ}$, twists upto $720^{\circ}$ have also been reported. ${ }^{1}$ Rupture at early gestation i.e. first and second trimester is mostly associated with uterine anomalies or cornual pregnancy.

\section{CASE}

An unbooked 25 -year- primigravida, at 26 weeks was referred to our hospital with complaints of loss of fetal movement for four days. There was an episode of severe pain abdomen one day back, which lasted for nearly one hour and relieved by medication. It

\section{CORRESPONDANCE}

Dr Ritu Tripathi

Department of Radiodiagnosis and Imaging, Institute of Medical Sciences, Banaras Hindu University,

Varanasi, India.

Email: ritugazal@gmail.com

Phone: +91-9161022333 was accompanied with mild per vaginal bleeding There was no history of vomiting, fever and loss of consciousness. There was no past or present history of instrumentation. On examination patient was conscious, oriented with stable vitals and minimal pallor. On abdominal examination, guarding and rigidity were present. Uterine contour could not be appreciated and fetal parts were felt superficially. On per vaginal examination, the cervix was closed and tubular. Haemoglobin was $9 \mathrm{mg} / \mathrm{dl}$ and total WBC count was 8,300 . All other blood investigations were within normal limits. Ultrasound reported bicornuate uterus with extrauterine fetus of 26 weeks gestation with absent cardiac activity (Figure 1). Presumptive diagnosis of bicornuate uterus with rupture of left horn and fetus in abdominal cavity was made.

Urgent laparotomy was performed with midline vertical incision, fetus and placenta were in abdominal cavity. Bicornuate uterus with single cervix (uterus bicornis unicollis) was present. There was torsion of gravid left horn (Figure 2) with rupture at medial wall of left horn. Left fallopian tube and round ligament were stretched across the left horn to the right side. A band was present between two horns connecting

The papers in this journal are published under the terms of the Creative Commons Attribution License. Users are allowed to read, download, copy, distribute, print, search, or link to the full texts of the articles in this journal without asking prior permission from the publisher or the author. 
bladder anteriorly and bowel posteriorly Fetus and placenta were extracted. Band was dissected and ruptured left horn was excised, hemostasis was secured leaving the non-ruptured non-gravid horn of uterus intact. Abdomen was closed in layers. Postoperative recovery was uneventful and patient was discharged on post-operative day seven. Patient was later investigated for urinary tract anomalies, which were absent. Patient was advised not to get pregnant for a year to allow healing and was warned of similar occurrence in next pregnancy. Patient was counseled for proper antenatal visits, early hospitalisation and elective caesarean at term in future pregnancy.

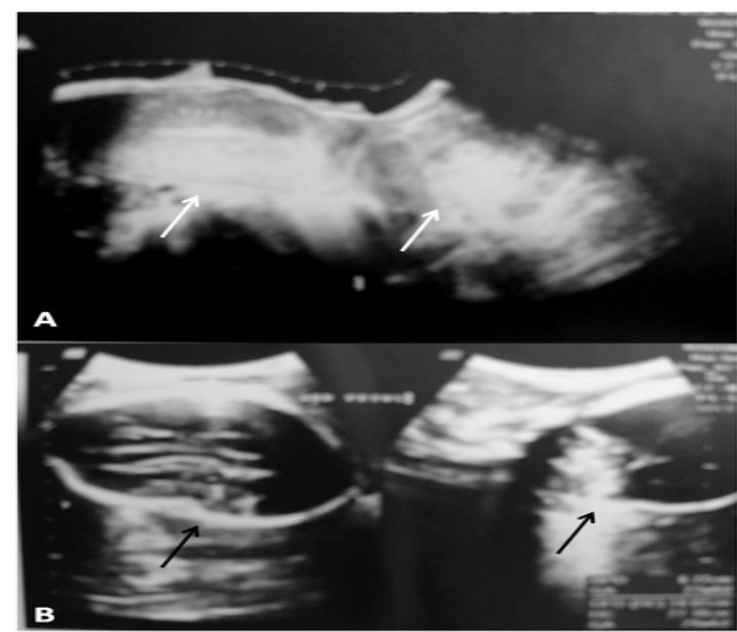

Figure 1. (A) USG showing a bicornuate uterus (white arrows) with relatively smaller right horn. Note the heterogeneity on the anterior wall of right horn (opposite to the right side white arrow) raising a suspicion of a possible rent. (B) Deformed fetal skull seen lying just under the maternal abdominal wall.

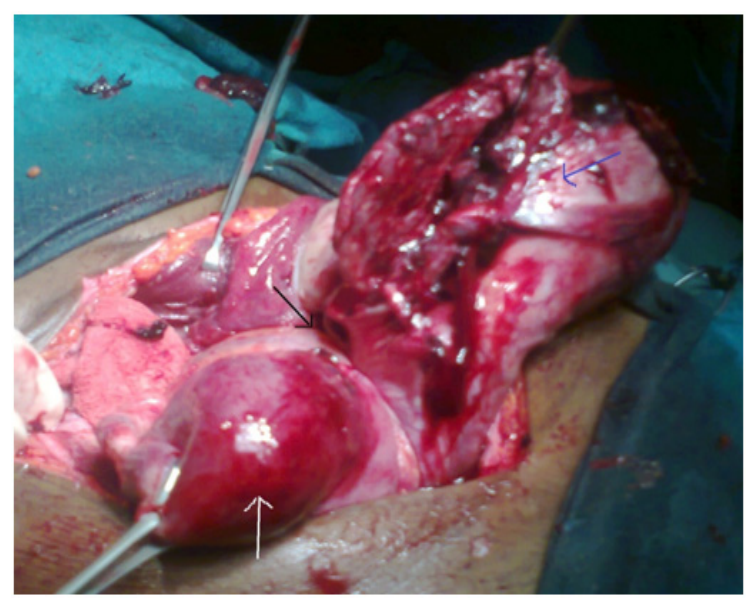

Figure 2. Photograph shows bicornuate uterus with rupture of left horn of uterus which underwent torsion due to a congenital band (black arrow) and unruptured right horn of uterus.

\section{COMMENT}

Uterine anomalies are associated with poor reproductive outcomes. Ruptured uterus is a life threatening obstetric problem. Rupture in primigravida in first or second trimester generally occurs in congenitally malformed uteri like unicornuate or bicornuate uterus with or without rudimentary horn. In this case it was bicornuate uterus, with rupture of left horn. Rupture was due to inability of malformed uterus to expand and axial torsion of bicornuate uterus around one of its horns which was held by congenital band. A midtrimester rupture generally occurs at fundus as against the medial wall rupture found in our case without any prior history of interference. This site of rupture might be due to maximum stress at medial wall of uterus due to torsion around congenital band.

Until 1992, only 212 cases with uterine torsion in pregnancy have been reported. We are reporting this case as it is very rare occurrence and only few other cases of ruptured bicornuate uteri associated with pregnancy have been reported..$^{2-4}$ Review of literature shows that clockwise rotation to right is common in pregnancy, but a torsion of sufficient degree which can arrest uterine circulation and cause acute abdominal crisis is rare. Mostly the cause is unknown. The presence of intra-abdominal adhesions, ovarian tumors, fetal malpresentation, mullerian uterine anomalies may be responsible for torsion. ${ }^{1}$ In our case torsion of gravid left horn was due to a congenital band present between two horns connecting bladder anteriorly and bowel posteriorly and resulted into rupture of the left horn at 26 weeks of gestation. Conventional ultrasonography is known to be poor at visualising uterine anomalies in pregnancy.More recently, three dimensional ultrasound scanning has been shown to be effective. ${ }^{5}$ It may be helpful in diagnosing such anomalies before rupture, which will help in decreasing the morbidity and mortality associated with rapid and massive haemoperitoneum occurring because of rupture. Achiron et $\mathrm{al}^{6}$ reported two cases of pre-rupture sonographic diagnosis of such cases. Nicholson et $\mathrm{al}^{7}$ have evaluated the role of "X sign" on Magnetic Resonance Imaging for evaluation of uterine torsion. Vagina is normally seen on Magnetic Resonance Imaging as an" H-shaped" structure but with torsion of uterus and upper vagina it appears as an "X- shaped" structure.

Haemodynamic stability in this patient was unusual as typically rupture presents with massive blood loss. This may be due to poor vascularity of the horn of uterus due to mullerian anomaly itself 
and due to torsion causing ischemia. Treatment usually involves removal of ruptured horn. As it leaves a scar on the uterus, its important to avoid pregnancy for at least one year. In addition, future pregnancy requires proper monitoring, early hospitalisation and elective caesarean section at term.

\section{REFERENCES}

1. Dua A, Fishwick K, Deverashetty B. Uterine torsion in pregnancy:a review. Internet J Gynecol Obstet. 2006;6(1).

2. Nahmanovici C. Abdominal pregnancy with a malformed uterus. J Gynecol Obstet Biol Reprod. 1980;9(3):369-71.

3. Kore S, Pandole A, Akolekar R, Vaidya N, Ambiye VR. Rupture of left horn of bicornuate uterus at twenty weeks of gestation. J Postgrad Med. 2000;46:39-40.

4. Mane S, Chaudhry R, Nandanwar Y. An unusual presentation of pregnancy in a bicornuate uterus. J Obstet Gynaecol India. 1994:44:154-5.

5. Wu M, Hsu C, Huan K. Detection of congenital Mullerian duct anomalies using three-dimensional ultrasound. J Clin Ultrasound. 1997;25:487-92.

6. Achiron R, Tadmor O, Kamar R, Aboulafia Y, Diamant Y. Prerupture ultrasound diagnosis of interstitial and rudimentary uterine horn pregnancy in second trimester: a report of two cases. J Reprod Med. 1992;37:89-92.

7. Nicholson WK, Coulson CC. Pelvic magnetic resonance imaging in the evaluation of uterine torsion. Obstet Gynecol. 2005;106:1186-7. 